\title{
Plant Polyphenols, Prenatal Development and Health Outcomes
}

\author{
Kaïs H. Al-Gubory
}

*Corresponding author: Kaïs H. Al-Gubory (PhD), Institut National de la RechercheAgronomique (INRA), Département de Physiologie Animale et Systèmesd'Elevage, UMR 1198 Biologie du Développement et de la Reproduction 78352 Jouy-en-Josascedex, France, Tel: 33134652362 ; Fax: 331 34652364; E-mail: kais.algubory@jouy.inra.fr

Received date: Dec 12, 2014, Accepted date: Dec 16, 2014, Published date: Dec 23, 2014

Copyright: @ 2014 Kaïs H. Al-Guboryet al. This is an open-access article distributed under the terms of the Creative Commons Attribution License, which permits unrestricted use, distribution, and reproduction in any medium, provided the original author and source are credited.

\section{Editorial}

The survival and health of aerobic organisms rely on their ability to perceive, tolerate and respond to various environmental stresses that otherwise compromise proper development and reproduction. Reactive oxygen species (ROS) are ubiquitous molecules that are generated as natural by-products of aerobic respiration and metabolism. Uncontrolled ROS generation appear to be responsible for oxidative damage to main cellular constituents, such as DNA, proteins, and lipids [1]. Fortunately, various dietary and cellular antioxidants maintain physiological levels of ROS, which in turn ensure biological functions without too much oxidative damage to the biological systems.

Dietary antioxidants, mainly polyphenols, are a wide variety of molecules that naturally occurring in vegetables, fruits, herbal plants, cereal grains, nuts, seeds, spices as well as plant-derived beverages $[2,3]$. Polyphenols, the most abundant plant organic compounds, have been suggested to play an important role in mammalian health promotion and disease prevention. The antioxidant potency of polyphenols explains the health benefits and disease prevention of diets rich in fruits and vegetables $[4,5]$.

Nutrition and maternal health before and during pregnancy are crucial for prenatal development and offspring health outcome. Imbalance between ROS production and ROS detoxification pathways (oxidative stress) induces prenatal developmental disorders, such as embryonic mortality, early spontaneous abortion, impaired foetal development, foetal death, premature delivery and low birth weight [6]. Impaired development in foetal life, a major problem in farm animals and humans, adversely impact adulthood health outcomes. Since, balanced dietary antioxidants before and during early pregnancy play important roles in embryonic implantation, placentation and organogenesis [7], intake of diets rich in polyphenols during the periconception period could improve maternal health and therefore could impact placental and foetal development, which in turn may reduce the risk of postnatal developmental disruption and pathologies in the adult age.

The in vivo confirmation and characterization of the beneficial effects of plant-derived polyphenols on prenatal developmental and health outcomes are of great interest because it may help in the design of nutritional antioxidant therapies for the prevention and treatment of prenatal developmental dysfunction and complications [8-10] and in utero programmable adulthood metabolic and endocrine disorders $[11,12]$. In this biomedical area, the use of plant by-products rich in polyphenolic compounds could be one of the therapeutic strategies to develop. Dietary supplementation with natural polyphenol-rich vegetables may open new opportunities to reduce gestational abnormalities in humans as well as in farm livestock with high risks of adverse pregnancy outcomes. Research is therefore needed to determine the efficacy of diet rich in polyphenols on pre- and postnatal developmental and health outcomes.

Maternal exposure to environmental pollutants during early pregnancy has a programming role in offspring physiology and metabolism that in turn increases the risk of disease in adulthood, including obesity, diabetes and cardiovascular disease $[13,14]$. Minimizing the environmental insults on pre-natal and post-natal developmental outcomes due to ROS-induced oxidative stress by cumulative exposure to various pollutants [15] is a challenge and requires a nutritional research program in an attempt to develop appropriate and applied prevention strategies. We can expect that periconception diet supplemented with natural plant polyphenols will provide reliable preventive therapeutic strategy against adverse effects of environmental pollutants on prenatal developmental and health outcomes.

Promoting an optimal maternal peri-conception nutrition will ensure optimal embryonic and foetal development and may reduce the risk of chronic diseases later in life. Animal models will be invaluable in determining the therapeutic potential of peri-conception supplementation of polyphenols in diet as an effective treatment against antioxidant deficiencies and/or environmental pollutants induced-oxidative stress, female infertility and prenatal developmental disorders and complications.

\section{References}

1. Halliwell B (2006) Reactive species and antioxidants. Redox biology is a fundamental theme of aerobic life. Plant Physiol 141: 312-322.

2. Carlsen MH, Halvorsen BL, Holte K, Bøhn SK, Dragland S, Sampson L, Willey C, Senoo H, Umezono Y, Sanada C, Barikmo I, Berhe N, Willett WC, Phillips KM, Jacobs DR Jr, Blomhoff R (2010) The total antioxidant content of more than 3100 foods, beverages, spices, herbs and supplements used worldwide. Nutr J 9: 3 .

3. Pérez-Jiménez J, Neveu V, Vos F, Scalbert A (2010) Identification of the 100 richest dietary sources of polyphenols: an application of the PhenolExplorer database. Eur J ClinNutr 64 Suppl 3: S112-120.

4. Del Rio D, Rodriguez-Mateos A, Spencer JP, Tognolini M, Borges G, Crozier A (2013) Dietary (poly)phenolics in human health: structures, bioavailability, and evidence of protective effects against chronic diseases. Antioxid Redox Signal 18: 1818-1892.

5. Liu RH (2013) Health-promoting components of fruits and vegetables in the diet. AdvNutr 4: 384S-92S.

6. Al-Gubory KH, Fowler PA, Garrel C (2010) The roles of cellular reactive oxygen species, oxidative stress and antioxidants in pregnancy outcomes. Int J Biochem Cell Biol 42: 1634-1650.

7. Cetin I, Berti C, Calabrese S (2010) Role of micronutrients in the periconceptional period. Hum Reprod Update 16: 80-95.

8. Miller SL, Wallace EM, Walker DW (2012) Antioxidant therapies: a potential role in perinatal medicine. Neuroendocrinology 96: 13-23. 
Citation: Kaïs H Al-Gubory (2014) Plant Polyphenols, Prenatal Development and Health Outcomes . Biol syst Open Access 3: e110. doi:

Page 2 of 2

9. Al-Gubory KH (2013) Maternal nutrition, oxidative stress and prenatal developmental outcomes. In: Agarwal A, Rizk B, Aziz N (Eds.), Studies on Women's Health, Oxidative Stress in Applied Basic Research and Clinical Practice, Springer Science and Business Media, Humana Press Inc; New York, pp. 1-31.

10. Al-Gubory KH (2014) Environmental Factors, Oxidative Stress, and Adverse Developmental Outcomes. In: Ismail L (Ed.), Systems Biology of Free Radicals and Antioxidants, Springer-Verlag Berlin and Heidelberg GmbH \& Co. KG, pp. 581-596.

11. Andriantsitohaina R, Auger C, Chataigneau T, Étienne-Selloum N, Li H, et al. (2012) Molecular mechanisms of the cardiovascular protective effects of polyphenols. Br J Nutr 108: 1532-1549.
12. Andriantsitohaina R, Duluc L, García-Rodríguez JC, Gil-del Valle L, Guevara-Garcia M, et al. (2012) Systems biology of antioxidants. ClinSci (Lond) 123: 173-192.

13. Strakovsky RS, Pan YX (2012) In utero oxidative stress epigenetically programs antioxidant defense capacity and adulthood diseases. Antioxid Redox Signal 17: 237-253.

14. Chen M, Zhang L (2011) Epigenetic mechanisms in developmental programming of adult disease. Drug Discov Today 16: 1007-1018.

15. Al-Gubory KH (2014) Environmental pollutants and lifestyle factors induce oxidative stress and poor prenatal development. Reprod Biomed Online 29: 17-31. 